\title{
Hacettepe Üniversitesi Sağlık Bilimleri Fakültesi Ergoterapi Bölümü Lisans Programındaki Derslerin Öğrencilerin ve Mezunların Bakış Açılarıyla İncelenmesi
}

Evaluation of Courses in The Undergraduate Program of the Hacettepe University, Faculty of Health Sciences, Department of Occupational Therapy by Students and Graduates

Fatma Nur UZUN ${ }^{1}$, Çiğdem ÖKSÜZ ${ }^{2}$

${ }^{1}$ Erg. Hacettepe Üniversitesi, Sağlık Bilimleri Fakültesi, Ergoterapi Bölümü, Ankara, Türkiye

2 Prof. Dr. Hacettepe Üniversitesi, Sağlık Bilimleri Fakültesi, Ergoterapi Bölümü, Ankara, Türkiye

\section{ÖZ}

\begin{abstract}
Amaç: Çalışmamızın amacı, Hacettepe Üniversitesi Ergoterapi lisans programındaki derslerin çalışma alanlarına katkılarını belirlemektir ve öğrencilmezunların bakış açısındaki farkları ortaya koymaktır. Gereç ve Yöntem: Katılımcılara nicel ve nitel soruları içeren (çalışma alanları, derslerin çalışma alanına ne kadar yarar sağladığı ve müfredatta bulunması gereken dersler) çevrimiçi anket uygulandı. Sonuçlar: Çalışmamıza 45 mezun, 45 öğrenci dahil edildi. Ergoterapi öğrencileri ve mezunlarının verdiği yanıtlara göre 96 dersin 73'ünün çalışma hayatına katkısı yüksek bulundu. Çalışma alanlarına en çok yarar sağlayan 'Motor Öğrenme' dersi iken en az yarar sağlayan ise 'Türk Dili 2' dersi olarak belirlendi. Tartışma: Çalışma sonuçlarımız Hacettepe Üniversitesi Ergoterapi lisans programında verilen teorik ve pratik bilgi birikiminin iş hayatı ile örtüştüğü, üniversite eğitimi sırasında öğrenilen akademik bilginin sektördeki uygulamalara yansıtıldığını göstermektedir. Ergoterapi eğitiminde kalite standartlarının oluşturulması ve bu standartların eğitim programına yansıtııması başarının temelini teşkil etmektedir.
\end{abstract}

Anahtar kelimeler: Müfredat; Öğrenciler; Eğitim

\section{ABSTRACT}

Purpose: The aim of our study is to determine the contributions of the courses in Hacettepe University Occupational Therapy program to the study areas and to reveal the differences between the perspectives of bachelor students'/ graduates' perspectives. Material and Methods: An online questionnaire including quantitative and qualitative questions (areas of study, how much lessons benefit the field of study, and courses that should be in the curriculum) was applied to the participants. Results: 45 graduates and 45 students were included in our study. According to the answers given by students and graduates, 73 of 96 courses were found to have a high contribution to working life. It was determined that the most beneficial course of study was the 'Motor Learning' course, while the least beneficial course was the 'Turkish Language 2' course. Discussion: Our study results show that the theoretical and practical knowledge accumulated in the Hacettepe University Occupational Therapy program coincides with the business life and the academic knowledge learned during university education is reflected in the practices in the sector. Establishing quality standards in occupational therapy education and reflecting these standards to the education program constitutes the basis of success.

Keywords: Curriculum; Students; Education 
Müfredat; öğrencinin başarılı olması için öğretim elemanının neler yapması gerektiğine yönelik amaçlar, içerik, öğrenme çevreleri ve yöntemlerin karakterize edilmesidir. Eğitim ve öğretim faaliyetlerinin bir plan ve program çerçevesinde yapılması süreklilik gerektirir. İşte bu süreklilik "program geliştirme" olarak isimlendirilir (Demirtaş, 2017).

Ergoterapi lisans eğitimi veren her bir kurumun müfredatının, Ergoterapi Ulusal Çekirdek Eğitim Programında (ERGO-ÇEP) tanımlanmış amaç ve ilkeler doğrultusunda geliştirmesi ergoterapi eğitiminin belirli standartlara göre yapılabilmesi açısından önemlidir. Teorik ve uygulamalı eğitimden oluşan ergoterapi lisans eğitim programının içeriğinin, ulusal özel yeterlilikler dahilinde belirlenmesi ve düzenlenmesi gerekmektedir. Ergoterapi lisans eğitim programı hazırlanırken; öğrenciye, ergoterapistin kullanacağı bilgi, beceri ve tutumların kazandırıması amaçlanır. Ergoterapi lisans eğitiminin; ergoterapi bilimi ile ilgili teori ve modellere, ergoterapi mesleği için gerekli mesleki uygulamalara ve becerilere yönelik eğitim içeriği, ergoterapi alanı ile ilişkili temel tıbbi bilimler, davranış bilimleri, sosyal ve beşeri bilimler ve bu bilimlerin içerikleri (anatomi, fizyoloji, sosyoloji, psikoloji, iletişim vb.), profesyonel kimlik, davranış ve etik değerlere yönelik eğitim içeriği, araştırma becerileri ve kanıta dayalı uygulamalara yönelik eğitim içeriği bileşenlerini kapsayacak şekilde düzenlenmesi önemlidir (European Network of Occupational Therapy in Higher Education [ENOTHE], 2004; Howard ve Lancee, 2000; Tuning Academ, 2014;Yükseköğretim Kurulu 2018).

Hacettepe Üniversitesi Sağlık Bilimleri Fakültesi Ergoterapi Bölümü lisans programı 2009 yılında, ergoterapist yetiştirmek amacı ile açılmıştır. Programın hazırlanma aşamasında Avrupa Ergoterapi Yükseköğrenim Ağı (European Network of Occupational Therapy in Higher Education- [ENOTHE]) den destek alınmıştır. Program yeterlilikleri 2006 yılında belirlenmiştir. Lisans programının akreditasyon çalışmalarına 2009 yılında başlanmıştır. Dünya Ergoterapi Federasyonu (World Federation of Occupational Therapy- [WFOT]) ile çalışmalar başlatılmış ve programın eğitim standartları WFOT tarafından onaylanmıştır (Hacettepe Üniversitesi, 2018). 2019 yılı içerisinde Sağlık Bilimleri Eğitim Programı Değerlendirme ve Akreditasyon Derneği (SABAK) tarafından Ergoterapi lisans eğitim programı 5 yıllık dönem için ulusal anlamda akredite edilmiştir (Sağlık Bilimleri Eğitim Programları Değerlendirme ve Akreditasyon Derneği, 2016).

Hacettepe Üniversitesi Ergoterapi lisans programının amacı, edindiği kuramsal ve pratik bilgileri birleştirebilen, kişi merkezli ergoterapi değerlendirme ve müdahale programı planlayıp uygulayabilen, kişilerin anlamlı ve amaçlı aktiviteler yolu ile günlük yaşamda bağımsızı̆̆ını ve yaşam kalitesini artırarak toplumsal katılımlarını sağlayan ergoterapistler yetiştirmektir. Klinik muhakeme etme, eleştirel düşünme ve interdisipliner bir şekilde çalışma becerisi ile kanıta dayalı uygulamalar yapabilmeyi başarabilen, mesleki ahlak ve yetkinliğe sahip ergoterapistler yetiştirmek ergoterapi lisans programının başka bir amacıdır (Hacettepe Üniversitesi, 2018).

Ergoterapi eğitim programlarının ulusal sağlıklsosyal politikalar ve eylem planları ile örtüşmesine özen gösterilmesi, eğitim programını geliştirilmesi, kuvvetli ve zayıf yönlerinin analiz edilmesine olanak sağlayan değerlendirmeler yapılması WFOT tarafından tavsiye edilmektedir. Ergoterapi lisans programının geliştirilebilmesi için, yerel ve ulusal yetkililerle iletişimin devam etmesi, diğer ergoterapi lisans eğitim programları ile ilişkilerin sürdürülmesi ve gelişim süreçleri ile ilgili geri bildirimlerin paylaşılması önerilmektedir. Paydaşlardan (öğretim elamanı, öğrenci, idari personel, mezunlar, işverenler, meslek odaları, üniversitenin diğer temsilcileri vb.) alınan geribildirimler müfredatın farklı bakış açıları ile geliştirilebilmesine olanak sağlar. Bu anlamda özellikle en önemli paydaşlar olan mezun ve öğrencilerin fikirlerini almak müfredatın güçlendirilebilmesi açısından önem (WFOT, 2017; ENOTHE, 2004). Hacettepe Üniversitesi Ergoterapi bölümünde yapılan bir çalışmada da paydaşların lisans ve klinik eğitimi hakkındaki görüşleri sorgulanmıştır. Çalışma sonucunda paydaşlar lisans eğitimini ve stajları iş yaşantısı için yeterli bulmamıştır (Sığırtmaç, Alan ve Öksüz, 2017).

Ergoterapi lisans programının geliştirilmesi için periyodik olarak değerlendirme yapılması gerekir (WFOT, 2017). Çalışmamızın amacı öğrenci ve mezunlardan alınan geribildirimlerden yararlanılarak Hacettepe Üniversitesi Ergoterapi Lisans programındaki derslerin çalışma alanlarında ne kadar yarar sağladığını belirlemektir. Ayrıca öğrencilmezunların bakış açıları arasındaki farkları ortaya koymak çalışmamızın bir diğer çıktısı olarak planlanmıştır.

\section{GEREÇ VE YÖNTEM}

Çalışmamıza Hacettepe Üniversitesi Sağlık Bilimleri 
Fakültesi Ergoterapi lisans programı 4. Sınıf öğrencisi ve aynı okuldan mezun olmuş ergoterapistler dahil edildi. Hacettepe Üniversitesi Sağlık Bilimleri Fakültesi Ergoterapi lisans programında öğrenim gören 1,2 ve 3 . sınıf öğrencileri programda yer alan derslerin tamamını almadığı için çalışma dışı bırakıldı.

Paydaş olarak seçilen son sınıf öğrencileri ve mezunların görüşlerini almak için 'Hacettepe Üniversitesi Sağlık Bilimleri Fakültesi Ergoterapi lisans programı ders değerlendirme anketi' ismi verilen sorular azarlar tarafından oluşturuldu. Bu soru bankası katılımcılara 2018-2019 bahar döneminde internet aracılığıyla (Google Formlar) gönderildi. Çevrimiçi anketin ilk sayfasında onam formu oluşturuldu. Çalışmaya katılmak isteyen bireyler bu sayfayı onayladıktan sonra sorulara ulaşabildi. Bu soru bankası kapsamında ilk olarak katılımcılara çalıştıkları/çalışmak istedikleri alanlar ve mezuniyet durumları soruldu. Íkinci bölümde Hacettepe Üniversitesi Ergoterapi lisans programında bulunan derslerin çalışma hayatında ne kadar yarar sağladığı sorgulandı ('0 hiç yarar sağlamadı','10 çok yarar sağladı' olacak şekilde oluşturuldu). Üçüncü bölümde ise Ergoterapi lisans programındaki hangi derslerin zorunlu dersten seçmeli ders kategorisine, hangi derslerin ise seçmeli dersten zorunlu ders kategorisine alınmasını istedikleri sorgulandı. Son olarak Ergoterapi lisans programına eklenmesi gereken konular sorgulandı.
Hacettepe Üniversitesi Ergoterapi lisans programında 96 ders bulunmaktadır. Bu derslerin içinde 2.sınıf ve 3.sınıf klinik eğitim (yaz stajı), 4.sınıfta ise 8 alanda 6 dersten oluşan klinik eğitim bulunmaktadır. Klinik eğitimler ise bölümün ünitelerinde verilmektedir. Bu üniteler; Duyu bütünleme, Pediatri, Az Gören Rehabilitasyonu, Onkolojik Rehabilitasyon, Ruh Sağlığında Ergoterapi, Mesleki Rehabilitasyon, El Rehabilitasyonu ve Geriatrik Rehabilitasyondur (Hacettepe Üniversitesi, 2018).

Ergoterapistlerin çalışma alanları çocuklar ve gençlerde ergoterapi uygulamaları, geriatrik rehabilitasyon, ruh sağlığı (psikiyatri), onkoloji, palyatif bakım, mesleki rehabilitasyon, el rehabilitasyonu, az gören rehabilitasyonu, dans ve hareket tedavisi, sürücü rehabilitasyonu, ev rehabilitasyonu, okullarda ergoterapi alanlarıdır (Hacettepe Üniversitesi, 2018).

\section{Istatistiksel Analiz}

İstatistiksel analizler Microsoft Excel 2017 yazılımı kullanılarak yapıldı. Tanımlayıcı analizler frekans, ortalama ve standart sapmalar olarak verildi.

\section{SONUÇLAR}

Hacettepe Üniversitesi Sağlık Bilimleri Fakültesi Ergoterapi bölümü son sınıf lisans öğrencileri (45 kişi) ve mezunlar (45 kişi) ile yapılan çalışma toplam 90 kişiyle tamamlandı. Veriler Şubat-Mayıs 2019 arasında toplandı. Katılımcıların çalışmak istediklerilçalıştıkları alanlar Tablo 1 de gösterildi. Katılımcıların en fazla çalıştıkları/çalışmak istedikleri alanın pediatrik rehabilitasyon alanı (\%52) olduğu belirlendi.

Tablo 1. Katılımcıların çalışmak istediklerilçalıştıkları alanlar

\begin{tabular}{lcc}
\hline Çalışma Alanı & Kişi sayısı & $\%$ \\
\hline Pediatrik Rehabilitasyon & 47 & 52 \\
\hline Psikiyatrik Rehabilitasyon & 17 & 19 \\
\hline El Rehabilitasyonu & 16 & 18 \\
\hline Diğer & 10 & 11 \\
\hline Toplam & 90 & 100 \\
\hline
\end{tabular}

Hacettepe Üniversitesi Ergoterapi lisans programı derslerinin öğrenci ve mezunlar yönünden çalışma hayatına ne kadar katkı sağladığı Tablo 2'de belirtilmiştir. Ergoterapi son sınıf öğrencileri ve mezunlarının verdiği yanıtlara göre 96 dersin 73'ünde derslerin çalışma hayatına olan katkıları ortalamanın üzerindedir. Elde edilen katkı puan ortalamalarına göre Motor Öğrenme $(X=8,51)$, en az katkı sağlayan dersin ise Türk Dili $2(X=3,07)$ olduğu katılımcılar tarafından belirtilmiştir. 
Son sınıf öğrencilerinin ve mezunların bakış açısından çalışma hayatında yararlı olduğu düşünülen dersler Tablo 3'te gösterilmiştir. Elde edilen katkı puan ortalamalarına göre öğrenciler tarafından çalışma hayatında en az yararlı olduğunu düşünülen dersler 'Atatürk İlkeleri ve İnkılap Tarihi1 $(X=3,49)$ ', 'Atatürk Illkeleri ve İnkılap Tarihi 2' dersi $(X=3,65)$ ve 'Türk Dili 1'dersi $(X=3,17)$ ve 'Türk Dili 2' dersi $(X=3,05)$ olarak belirlenmiştir. Mezunlara göre ise çalışma hayatında en az yararlı olduğunu düşünülen dersler 'Türk Dili1' dersi $(X=3,15)$, 'Türk Dili 2' dersi $(X=3,09)$ ve 'Özel Gereksinimli Çocuklarda Bağımsız Yaşam' dersidir ( $X=3,70)$.

Elde edilen katkı puan ortalamalarına göre Pediatri alanında en yararlı ders 'Büyüme Gelişim' dersi $(X=8,79)$ seçilirken, Psikiyatri alansında 'Performans alanları: Duyu Motor' dersi $(X=8,71)$, El Rehabilitasyonu alanında ise 'El Rehabilitasyonu ve Ergoterapi' dersi $(X=9,36)$ en yararlı ders olarak seçilmiştir. Diğer alanında ise en yararlı ders 'Günlük Yaşam Aktiviteleri' dersi $(X=9.2)$ seçilmiş̧ir.

Katılımcılar, en çok 'Ergoterapi'de Yönetim Organizasyon ve Kayıt Sistemleri' $(n=24)$ dersinin zorunlu dersten seçmeli ders kategorisine geçirilmesi gerektiğini düşünmektedir. Zorunlu dersten seçmeli ders kategorisine geçirilmesini düşündükleri diğer dersler ise 'Araştırma Yöntemleri' dersi (n=3), 'Öğrenci Mezuniyet Projesi' dersi $(n=2)$, 'Sağılık İletişimi' dersi $(n=2)$, 'Ergoterapi'de Etik ve Profesyonel Gelişim' dersi $(n=1)$, 'Ortez ve 'dersi $(n=1)$, 'Türk Dili' dersi $(n=1)$ ve 'Ingilizce' dersidir $(n=1)$.

Katılımcılar, en çok 'Kanser ve Ergoterapi' dersinin $(n=26)$, 'Yeni Doğanda Duyu Bütünlüğü' dersinin $(n=23)$, 'Yutma Bozuklukları' dersinin ( $n=11)$, 'Kardiyak ve Pulmoner Rehabilitasyonda Ergoterapi' dersinin $(n=7)$ seçmeli dersten zorunlu ders kategorisine geçirilmesini önermiştir. Seçmeli dersten zorunlu ders kategorisine geçirilmesi önerilen diğer dersler ise 'Stresle Başa Çıkma Yöntemleri' dersi $(n=5)$, 'Dans ve Hareket Tedavisi ve Ergoterapi' dersi $(n=3)$, 'Drama' dersi $(n=3)$, 'Bakım Verenlerde Ergoterapi' dersi $(n=2)$, 'Bel Boyun Okulu' dersi ( $n=2)$, 'Okul Danışmanlığı' dersi $(n=2)$, 'Rehabilitasyonda Hayvan Destekli Yaklaşımlar' dersi $(n=2)$, 'Rehabilitasyonda İnterdisipliner Çalışma' dersi $(n=1)$, 'Görme Özürlülerde Bağımsız Yaşam' dersidir $(n=1)$.

Öğrenci ve mezunlar 'Danışan ile Görüşme Teknikleri' $(n=10)$, Hastalıklar, Tanı ve Müdahaleleri' $(n=8)$, 'Klinik Eğitime Hazırlık' $(n=8)$, 'Oyun Terapisi' $(n=7)$, 'Duyu Bütünleme' $(n=5)$ ve 'Illk Yardım' $(n=5)$ konularının müfredata eklenmesini tavsiye etmişlerdir. Müfredata eklenmesi belirtilen diğer konular ise 'Gelişim Psikolojisi' ( $n=3)$, 'Vaka Analizi' ( $n=2)$, 'Makale Okuma ve Anlama' ( $n=2)$, 'Çocuklarla Iletişim' $(n=1)$, 'Eş Cinsellere Yönelik Rehabilitasyon Yaklaşımları' $(n=1)$, 'Ergoterapi Tanıtımı-Reklamı-Kariyer planı $(n=1)$, 'Ince Motor Beceri Aktiviteleri' $(n=1)$, 'Ergoterapi Kanunları ve Hakları' $(n=1)$, 'Sosyal Hizmet' $(n=1)$, 'Patoloji' $(n=1)$, 'Farmakoloji' $(n=1)$, 'Detaylı Büyüme Gelişim-Anatomi-Fizyoloji-Nöroanatomi' $(n=1)$ 'dir.

Tablo 2. X Üniversitesi Ergoterapi Lisans Programı derslerinin çalışma hayatına sağladığı katkı puanları

\begin{tabular}{|c|c|c|c|c|c|}
\hline DERSLER & $\begin{array}{l}\text { Zorunlul } \\
\text { Seçmeli }\end{array}$ & $\mathbf{x}$ & $\begin{array}{l}\text { Zorunlul } \\
\text { Seçmeli }\end{array}$ & DERSLER & $\mathbf{x}$ \\
\hline Ergoterapi'ye Giriş & Zorunlu & 5,91 & Zorunlu & $\begin{array}{l}\text { Performans Alanları: } \\
\text { psikososyal }\end{array}$ & 7,63 \\
\hline Sağlık Stratejileri & Zorunlu & 5,86 & Zorunlu & $\begin{array}{l}\text { Kas İskelet Sistemi } \\
\text { Fonksiyonları } \\
\text { Yetersizliklerinde Ergoterapi }\end{array}$ & 8,12 \\
\hline Ergoterapi Teorileri & Zorunlu & 7,39 & Zorunlu & Mesleki Uygulama: 2.Sınıf & 8,10 \\
\hline $\begin{array}{l}\text { Ergoterapi'de Etik ve Profesyonel } \\
\text { Gelişim }\end{array}$ & Zorunlu & 6,28 & Zorunlu & İngilizce 4 & 3,39 \\
\hline İngilizce 1 & Zorunlu & 3,40 & Seçmeli & Bakım Verenlerde Ergoterapi & 6,13 \\
\hline
\end{tabular}




\begin{tabular}{|c|c|c|c|c|c|}
\hline Türk Dili 1 & Zorunlu & 3,16 & Seçmeli & Kanser ve Ergoterapi & 6,66 \\
\hline Büyüme Gelişim & Zorunlu & 7,28 & Seçmeli & Öz Yönetim & 5,58 \\
\hline $\begin{array}{l}\text { Ergoterapi'de İletişim ve Görüşme } \\
\text { Teknikleri }\end{array}$ & Seçmeli & 4,53 & Seçmeli & İşaret Dili 2 & 4,41 \\
\hline Yaşam Kalitesi & Seçmeli & 6,86 & Zorunlu & Nörogelişimsel Bozukluklar & 7,51 \\
\hline Bilim Sanat Felsefe & Seçmeli & 5,66 & Zorunlu & $\begin{array}{l}\text { Geriatrik Rehabilitasyonda } \\
\text { Ergoterapi }\end{array}$ & 7,03 \\
\hline Drama & Seçmeli & 6,72 & Zorunlu & $\begin{array}{l}\text { Probleme Dayalı Ergoterapi } \\
\text { Ugulamaları }\end{array}$ & 7,51 \\
\hline $\begin{array}{l}\text { Ergoterapi Sanatsal Yaklaşımlar } \\
\text { Resim ve El Sanatları }\end{array}$ & Seçmeli & 2,88 & Zorunlu & $\begin{array}{l}\text { Koruyucu Ergoterapi ve } \\
\text { Çevresel Düzenlemeler }\end{array}$ & 7,00 \\
\hline Araştırma Yöntemlerine Giriş & Zorunlu & 4,17 & Zorunlu & $\begin{array}{l}\text { Ergoterapi Yönetim } \\
\text { Organiasyon ve Kayıt } \\
\text { Sistemleri }\end{array}$ & 4,26 \\
\hline Anatomi & Zorunlu & 7,44 & Zorunlu & Psikiyatride Ergoterapi & 7,21 \\
\hline $\begin{array}{l}\text { Temel Bilgi ve İletişim } \\
\text { Teknolojilerinin Kullanımı }\end{array}$ & Zorunlu & 4,55 & Zorunlu & $\begin{array}{l}\text { El Rehabilitasyonu ve } \\
\text { Ergoterapi }\end{array}$ & 8,31 \\
\hline Ergoterapi de Aktiviteler & Zorunlu & 7,78 & Seçmeli & $\begin{array}{l}\text { Engelli Bireylerin İnsan } \\
\text { Hakları }\end{array}$ & 5,51 \\
\hline Fizyoloji & Zorunlu & 7,15 & Seçmeli & $\begin{array}{l}\text { Engellilerde Spor ve } \\
\text { Rekreasyon }\end{array}$ & 5,68 \\
\hline İngilizce 2 & Zorunlu & 3,28 & Seçmeli & Diyabet ve Ergoterapi & 5,69 \\
\hline Temel Psikoloji & Zorunlu & 5,93 & Seçmeli & $\begin{array}{l}\text { Görme Özürlülerde Bağımsız } \\
\text { Yaşam }\end{array}$ & 4,69 \\
\hline Engellilik Sosyolojisi & Zorunlu & 7,14 & Seçmeli & Bel Boyun Okulu & 5,94 \\
\hline Türk Dili 2 & Zorunlu & 3,07 & Seçmeli & $\begin{array}{l}\text { Rehabilitasyonda } \\
\text { Interdisipliner Yaşam }\end{array}$ & 6,15 \\
\hline Stresle Başa Çıkma Yöntemleri & Seçmeli & 6,75 & Seçmeli & $\begin{array}{l}\text { Özel Gerek. Çocuk Bağımsız } \\
\text { Yaşam }\end{array}$ & 3,89 \\
\hline $\begin{array}{l}\text { Şiddete Maruz Kalanlarda } \\
\text { Rehabilitasyon }\end{array}$ & Seçmeli & 4,80 & Seçmeli & İngilizce 5 & 3,31 \\
\hline Müzik-Algılama-İletişim & Seçmeli & 5,54 & Zorunlu & Mesleki Rehabilitasyon & 6,50 \\
\hline Atatürk İlkeleri ve İnkilap Tarihi 1 & Zorunlu & 3,50 & Zorunlu & $\begin{array}{l}\text { Nörogelişimsel Bozukluklarda } \\
\text { Ergoterapi }\end{array}$ & 7,92 \\
\hline Performans Alanları: Duyu Motor & Zorunlu & 8,29 & Zorunlu & $\begin{array}{l}\text { Toplum Temelli } \\
\text { Rehabilitasyon }\end{array}$ & 6,51 \\
\hline Performans Alanları: Kognitif & Zorunlu & 8,12 & Zorunlu & Ortez ve Biyomekanik & 6,64 \\
\hline
\end{tabular}




\begin{tabular}{|c|c|c|c|c|c|}
\hline $\begin{array}{l}\text { Temel Ölçme ve Değerlendirme } \\
\text { Teknikleri }\end{array}$ & Zorunlu & 7,34 & Zorunlu & Motor Öğrenme & 8,51 \\
\hline Fonksiyonel Kinezyoloji & Zorunlu & 7,70 & Zorunlu & Mesleki Uygulama: 3. Sınıf & 8,38 \\
\hline İngilizce 3 & Zorunlu & 6,06 & Seçmeli & Dans ve Hareket Tedavisi & 5,30 \\
\hline Nöroanatomi & Zorunlu & 7,34 & Seçmeli & $\begin{array}{l}\text { Mental Sağlık Problemlerinde } \\
\text { Mesleki Rehabilitasyon }\end{array}$ & 6,30 \\
\hline Engellilik ve Sağlık Politikaları & Seçmeli & 4,92 & Seçmeli & Kadın Sağlığı & 4,57 \\
\hline Toplumsal Katılım & Seçmeli & 5,30 & Seçmeli & $\begin{array}{l}\text { Yeni Doğanda Duyu } \\
\text { Bütünlüğü }\end{array}$ & 7,56 \\
\hline Yeme Bozuklukları & Seçmeli & 6,19 & Seçmeli & $\begin{array}{l}\text { Ergoterapist ve Okul } \\
\text { Danışmanlığı }\end{array}$ & 6,30 \\
\hline Stigma ve Ergoterapi & Seçmeli & 5,84 & Seçmeli & İngilizce 6 & 3,27 \\
\hline İşaret Dili 1 & Seçmeli & 4,66 & Zorunlu & Mesleki Uygulama: Erişkin & 7,18 \\
\hline Atatürk İlke ve İnkılap Tarihi 2 & Zorunlu & 3,67 & Zorunlu & Mesleki Uygulama: Onkoloji & 7,92 \\
\hline Günlük Yaşam Aktiviteleri & Zorunlu & 8,01 & Zorunlu & Mesleki Uygulama: Psikiyatri & 6,66 \\
\hline Yardımcı Teknoloji & Zorunlu & 6,92 & Zorunlu & Mesleki Uygulama: Pediatri & 7,77 \\
\hline $\begin{array}{l}\text { Mesleki Uygulama: Mesleki } \\
\text { Rehabilitasyon }\end{array}$ & Zorunlu & 6,15 & Seçmeli & $\begin{array}{l}\text { Rehabilitasyonda Hayvan } \\
\text { Destekli Yaklaşımlar }\end{array}$ & 5,29 \\
\hline Mesleki Uygulama: Duyu Bütünlüğü & Zorunlu & 7,40 & Seçmeli & Engelsiz Üniversite & 5,46 \\
\hline Mesleki Uygulama: Geriatri & Zorunlu & 6,88 & Seçmeli & $\begin{array}{l}\text { Rehabilitasyonda } \\
\text { Biyopsikososyal Yaklaşımlar }\end{array}$ & 5,79 \\
\hline $\begin{array}{l}\text { Mesleki Uygulama: Az Gören } \\
\text { Rehabilitasyonu }\end{array}$ & Zorunlu & 6,98 & Zorunlu & Öğrenci Mezuniyet Projesi & 6,60 \\
\hline $\begin{array}{l}\text { Kanıta Dayalı Ergoterapi } \\
\text { Uygulamaları }\end{array}$ & Zorunlu & 6,73 & Zorunlu & Sağlık İletişimi & 5,92 \\
\hline Araştırma Yöntemleri & Zorunlu & 5,89 & Seçmeli & $\begin{array}{l}\text { Pulmoner Rehabilitasyon da } \\
\text { Ergoterapi }\end{array}$ & 5,27 \\
\hline Sürücü Rehabilitasyonu & Seçmeli & 5,53 & Seçmeli & $\begin{array}{l}\text { Rehabilitasyonda Sanal } \\
\text { Gerçeklik }\end{array}$ & 6,58 \\
\hline Yutma Bozukluklarında Ergoterapi & Seçmeli & 6,43 & Seçmeli & $\begin{array}{l}\text { Çalışma Ergonomisi ve } \\
\text { İşle İlgili Risk Faktörleri }\end{array}$ & 5,67 \\
\hline $\begin{array}{l}\text { Kardiyak Rehabilitasyonda } \\
\text { Ergoterapi }\end{array}$ & Seçmeli & 6,02 & Seçmeli & Afetler ve Toplumsal Katılım & 4,76 \\
\hline
\end{tabular}


Tablo 3. Son sınıf öğrencilerinin ve mezunların çalışma hayatında yararlı olduğunu düşündükleri derslerin ortalama katkı puanları

\begin{tabular}{|c|c|c|c|}
\hline Son Sınıf Öğrencileri & & Mezunlar & \\
\hline Dersler & $\mathrm{X}$ & Dersler & $\mathrm{X}$ \\
\hline Mesleki Uygulama: 3. Sınıf & 8,64 & Motor Öğrenme & 8,50 \\
\hline Motor Öğrenme & 8,52 & EI Rehabilitasyonu ve Ergoterapi & 8,39 \\
\hline Mesleki Uygulama: 2. Sınıf & 8,42 & Performans Alanları: Duyu Motor & 8,29 \\
\hline Performans Alanları: Duyu Motor & 8,29 & Mesleki Uygulama: Onkoloji & 8,20 \\
\hline Performans Alanları: Kognitif & 8,29 & $\begin{array}{l}\text { Kas İskelet Sistemi Fonksiyonu } \\
\text { Yetersizliklerinde Ergoterapi }\end{array}$ & 8,16 \\
\hline El Rehabilitasyonu ve Ergoterapi & 8,23 & Mesleki Uygulama: 3. Sınıf & 8,11 \\
\hline $\begin{array}{l}\text { Kas İskelet Sistemi Fonksiyonu } \\
\text { Yetersizliklerinde Ergoterapi }\end{array}$ & 8,09 & Büyüme Gelişim & 8,04 \\
\hline Günlük Yaşam Aktiviteleri & 7,98 & Günlük Yaşam Aktiviteleri & 8,04 \\
\hline Nörogelişimsel Bozukluklar. Erg & 7,95 & Kanser ve Ergoterapi & 8,00 \\
\hline Mesleki Uygulama: Duyu Bütün. & 7,86 & Performans Alanları: Kognitif & 7,96 \\
\hline Ergoterapi'de Aktiviteler & 7,78 & Fonksiyonel Kinezyoloji & 7,96 \\
\hline Mesleki Uygulama: Pediatri & 7,77 & $\begin{array}{l}\text { Nörogelişimsel Bozukluklarda } \\
\text { Ergoterapi }\end{array}$ & 7,89 \\
\hline Yeni Doğanda Duyu Bütünlüğü & 7,68 & Mesleki Uygulama: Erişkin & 7,88 \\
\hline Mesleki Uygulama: Onkoloji & 7,64 & Stresle Başa Çıkma Yöntemleri & 7,88 \\
\hline Nörogelişimsel Bozukluklar & 7,49 & Performans Alanları: Psikososyal & 7,87 \\
\hline Fonksiyonel Kinezyoloji & 7,44 & Mesleki Uygulama: 2. Sınıf & 7,78 \\
\hline $\begin{array}{l}\text { Probleme Dayalı Ergoterapi } \\
\text { Uygulamaları }\end{array}$ & 7,43 & Ergoterapide Aktiviteler & 7,78 \\
\hline Nöroanatomi & 7,46 & Mesleki Uygulama: Pediatri & 7,77 \\
\hline Performans Alanları: Psikososyal & 7,40 & Psikiyatride Ergoterapi & 7,73 \\
\hline Öğrenci Mezuniyet Projesi & 7,39 & Geriatrik Rehabilitasyonda Ergoterapi & 7,69 \\
\hline
\end{tabular}


Tablo 4. Son sınıf öğrencilerinin ve mezunların belirli çalışma alanlarına göre yarar sağladığını düşündükleri derslerin ortalama katkı puanları

\begin{tabular}{|c|c|c|c|}
\hline Çalışma alanı & Dersler & Zorunlu/Seçmeli & $\mathbf{x}$ \\
\hline \multicolumn{4}{|l|}{ Pediatri } \\
\hline & Büyüme Gelişim & Zorunlu & 8,79 \\
\hline & Motor Öğrenme & Zorunlu & 8,51 \\
\hline & $\begin{array}{l}\text { Kas İskelet Sistemi Fonksiyonu Yetersizliklerinde } \\
\text { Ergoterapi }\end{array}$ & Zorunlu & 8,30 \\
\hline & El Rehabilitasyonu ve Ergoterapi & Zorunlu & 8,26 \\
\hline & Performans Alanları: Kognitif & Zorunlu & 8,21 \\
\hline & Mesleki Uygulama: 3.sınıf & Zorunlu & 8,21 \\
\hline & Performans Alanları: Duyu Motor & Zorunlu & 8,13 \\
\hline & Mesleki Uygulama: 2.sınıf & Zorunlu & 8,11 \\
\hline & Yaşam Kalitesi & Seçmeli & 8,09 \\
\hline & Yeni Doğanda Duyu Bütünlüğü & Seçmeli & 8,07 \\
\hline \multicolumn{4}{|l|}{ Psikiyatri } \\
\hline & Performans Alanları: Duyu Motor & Zorunlu & 8,71 \\
\hline & Performans Alanları: Kognitif & Zorunlu & 8,65 \\
\hline & Mesleki Uygulama: 3.sınıf & Zorunlu & 8,56 \\
\hline & Ergoterapi'de Aktiviteler & Zorunlu & 8,47 \\
\hline & Nörogelimsel Bozukluklarda Ergoterapi & Zorunlu & 8,38 \\
\hline & Performans Alanları: Psikososyal & Zorunlu & 8,35 \\
\hline & Günlük Yaşam Aktiviteleri & Zorunlu & 8,29 \\
\hline & Engellilik Sosyolojisi & Zorunlu & 8,19 \\
\hline & Ergoterapi Teorileri & Zorunlu & 8,18 \\
\hline & Motor Öğrenme & Zorunlu & 8,13 \\
\hline \multicolumn{4}{|l|}{ EI } \\
\hline \multicolumn{4}{|c|}{ Rehabilitasyonu } \\
\hline & El Rehabilitasyonu ve Ergoterapi & Zorunlu & 9,36 \\
\hline & Motor Öğrenme & Zorunlu & 9,13 \\
\hline & Fonksiyonel Kinezyoloji & Zorunlu & 8,88 \\
\hline & Mesleki Uygulama: 2.Sınıf & Zorunlu & 8,56 \\
\hline & Mesleki Uygulama: 3.Sınıf & Zorunlu & 8,56 \\
\hline & $\begin{array}{l}\text { Kas İskelet Sistemi Fonksiyonu Yetersizliklerinde } \\
\text { Ergoterapi }\end{array}$ & Zorunlu & 8,19 \\
\hline & Mesleki Uygulama: Onkoloji & Zorunlu & 8,00 \\
\hline & Performans Alanları: Duyu Motor & Zorunlu & 7,88 \\
\hline & Ortez ve Biyomekanik & Zorunlu & 7,75 \\
\hline & Probleme Dayalı Ergoterapi Uygulamaları & Zorunlu & 7,60 \\
\hline \multicolumn{4}{|l|}{ Diğer } \\
\hline & Günlük Yaşam Aktiviteleri & Zorunlu & 9,2 \\
\hline & Mesleki Uygulama: Pediatri & Zorunlu & 9,11 \\
\hline & Performans Alanları: Duyu Motor & Zorunlu & 9 \\
\hline & Yeni Doğanda Duyu Bütünlüğü & Zorunlu & 9 \\
\hline & Nörogelişimsel Bozukluklarda Ergoterapi & Zorunlu & 8,9 \\
\hline & Performans Alanları: Kognitif & Zorunlu & 8,7 \\
\hline & Geriatrik Rehabilitasyonda Ergoterapi & Zorunlu & 8,6 \\
\hline & Mesleki Uygulama: 3.Sınıf & Zorunlu & 8,6 \\
\hline & Mesleki Uygulama: 2.Sınıf & Zorunlu & 8,5 \\
\hline & Mesleki Uygulama: Onkoloji & Zorunlu & 8,5 \\
\hline
\end{tabular}




\section{TARTIŞMA}

Üniversitelerin eğitim programlarının yapıları öğrenci merkezli eğitim anlayışına dayandırımalıdır. Bu kapsamda öğrencilerin kendi tercihleri doğrultusunda uzmanlaşmalarına izin verilmelidir (Yükseköğretim Kalite Kurulu, ty). Müfredat geliştirme ve kalite çalışmaları kapsamında en önemli paydaş olarak gösterilen öğrenci ve mezunların, Ergoterapi bölümü lisans programı hakkındaki görüşlerini sorgulamak, müfredatın kalitesinin geliştirilmesi ve devamı için önemlidir. Bizim çalışmamızda da Hacettepe Üniversitesi Sağlık Bilimleri Fakültesi Ergoterapi lisans programında verilen 96 dersin 73'ünde, derslerin çalışma alanında ortalama puanın üzerinde yarar sağladığı sonucuna ulaşımıştır. Bu sonuç, Hacettepe Üniversitesi Ergoterapi lisans programında verilen teorik ve pratik bilgi birikiminin iş hayatı ile örtüştüğü, üniversite eğitimi sırasında öğrenilen akademik bilginin sektördeki uygulamalara yansıtıldığını göstermektedir. Ergoterapi eğitiminde kalite standartlarının oluşturulması ve bu standartların eğitim programına yansıtılması başarının temelini teşkil etmektedir. İş hayatına daha az katkı sağladığı düşünülen dersler genellikle İngilizce, Türk Dili, Atatürk Illkeleri ve İnkılap Tarihi gibi dersleridir. Bu dersler üniversite müfredatında olması gereken zorunlu dersleri olduğundan ve bu dersler kapsamında Ergoterapi bölümü mesleki bilgilerine yer verilmediğinden bu derslerin çalışma hayatına yararının katııımcılar tarafından düşük bulunduğu düşünülebilir. Ergoterapistlik mesleği sırasında üniversite eğitimi aşamasında elde edilen bilgilerin ve uygulamaların meslek hayatında kullanılması beklenmektedir (Tuning Academy, 2014).

Çalışmamızın sonuçlarına göre katıımcı gözünden müfredat programındaki çalışma hayatına en çok yarar sağlayan ders 'Motor Öğrenme' dersidir. Bu dersin içeriğinde beyin plastisitesi, kısıtlanmış hareket tedavisi ve pratiği, motor öğrenme teorileri, prensipleri ve klinik uygulamaya aktarıması, pediatrik rehabilitasyonda motor öğrenme temelli yaklaşımlar, hedef odaklı ve görev odaklı eğitim gibi klinikte pek çok farklı alanlarda temel teşkil eden konuların hem pratik hem de teorik dersler ile pekiştirilmesi nedeniyle çalışma hayatına en çok katkı sağlayan ders olarak belirtildiğini düşünmekteyiz (Hacettepe Üniversitesi, 2018). Katıımcılar tarafından, çalışma hayatına en çok yarar sağlayan stajın ise 'Pediatri' stajı olduğu bulunmuştur. Günümüz şartlarında mezun ergoterapistlerin daha çok pediatri alanında istihdam ediliyor olmasının bu sonucu doğurduğu düşünülmektedir. Aynı şekilde 'Yeni Doğanda Duyu Bütünlüğü' dersinin katılımcılar tarafından seçmeli dersten zorunlu ders kategorisine eklenmesi gereken ders olarak seçilmesinin de bu nedenle olduğu kanısındayız.

Ergoterapistlik mesleğinin bir uygulama mesleği olduğu düşünüldüğünde pratik ağırlıkları fazla olan 'Performans alanları: Duyu Motor', 'El Rehabilitasyonu ve Ergoterapi' ve 'Günlük Yaşam Aktiviteleri' dersleri ile öğrencilerin ilk kez süpervisör gözetiminde kendi sorumluluklarında değerlendirme yöntemlerini kullanma, kişi merkezli ergoterapi müdahale programı oluşturma ve uygulama ve farklı alanlarda problem çözme becerisini kullanma şansı buldukları ders olan 'Mesleki Uygulama 3.sınıf' dersinin en çok yarar sağlayan dersler olması doğaldır. Ergoterapistlerin okulda uygulama fırsatı bulamadıkları konularda çalışma hayatının özellikle ilk dönemlerinde kaygııı olduklarını belirtmişlerdir (Hodgetts, Hollis, Triska, ve ark., 2007; Lunenburg, 2011). Ergoterapi eğitimi çerçevesinde yeterli düzeyde uygulama yapma fırsatı öğrencilere verilmelidir (ENOTHE, 2004) .

Katılımcılar, 'Kanser ve Ergoterapi' ve 'Yeni Doğanda Duyu Bütünlüğü' gibi konularınergoterapi müfredatına eklenmesi gerektiğini belirtmişlerdir. Ergoterapi müfredatındaki stajların alanlarının (Mesleki Uygulama: Onkoloji, Duyu Bütünlüğü) bu derslerin teorik bilgileriyle ilişkili olması bulgularımızı desteklemektedir (Hacettepe Üniversitesi, 2018).Diğer üniversitelerde de bu eğitimin zorunlu müfredat eğitim içeriğinde olduğu görülmektedir. (USC Chan Division, 2019). Bu gibi eğitimlerin zorunlu ders müfredat programına dahil edilmemesi mezuniyet sonrasında ergoterapistlerin farklı kurslar ile bu alanlardaki eksikliklerini yaşam boyu öğrenme stili ile tamamlamaya yönlendirilmektedir.

Yükseköğretim Kalite Kurumu iç kalite güvence sisteminin önemli bir üyesi olan öğrenci ve mezunlarda oluşan paydaşların yükseköğretim kurumlarında kalite güvence sisteminin anahtar bileşenlerinden biri olduğunu belirtmiştir (Yükseköğretim Kalite Kurulu, tk). Çalışmamıza dahil olan 4. sınıf öğrencileri ve mezunların, her ne kadar çalışmanın amacının dersin çalışma alanına katkısını sorgulamak olduğu kendilerine ayrıntılı olarak açıklanmış olsa da dersin işleyişi, öğretim üyesinin derse katkısı, dersin süresi ve sınav içerikleri gibi farklı parametrelerden etkilenmiş olabileceklerini düşünmekteyiz. $\mathrm{Bu}$ durum çalışmamızın önemli bir limitasyonu olarak karşımıza çıkmaktadır. Bunun yanında, literatürdeki çalışmalara paralel olarak derslerin içeriği, öğrenim çıktıları ve 
işleyişi hakkındaki görüşlerinin ele alındığı daha ayrıntılı çalışmalara da intiyaç duyulmaktadır (Hodgetts ve ark., 2007).

On yıldır ergoterapi lisans eğitimi veren Hacettepe Üniversitesi Sağlık Bilimleri Fakültesi Ergoterapi Bölümünde yapılan bu çalışmanın sonuçları paydaşların eğitime bakış açısını ifade etmesi açısından önemlidir. Ergoterapi müfredatının farklı paydaşların gözünden değerlendirildiği çalışmaların belli aralıklarla tekrarlanması ve yaygınlaştırılması Ergoterapi Bölümlerinin müfredatlarının gelişimine katkı sağlayacak ve müfredatların kalitesini arttıracaktır. Organizasyonlarda kalitenin arttırılmasını hedef alan toplam kalite yönetimi felsefesinin ergoterapi eğitimi veren bütün üniversitelerde benimsenmesi ve kalitenin sağlanması konusunda titizlik gösterilmesi yetiştirilecek öğrenci profilinin kalitesinin artmasına ve Türkiye'de ergoterapi mesleğinin layıkıyla uygulanmasına olanak sağlayacaktır.

\section{Araştırmacıların Katkı Oranı}

Fikir/Kavram: Fatma Nur UZUN

Tasarım: Fatma Nur UZUN ve Çiğdem ÖKSÜZ

Denetleme/Danışmanlık: Çiğdem ÖKSÜZ

Veri Toplama ve/veya İşleme: Fatma Nur UZUN

Analiz ve/veya Yorum: Fatma Nur UZUN ve Çiğdem ÖKSÜZ

Kaynak Taraması: Fatma Nur UZUN

Makalenin Yazımı: Fatma Nur UZUN ve Çiğdem ÖKSÜZ

Eleştirel İnceleme: Çiğdem ÖKSÜZ

\section{Çıkar Çatışması Beyanı}

Yazarlar arasında çıkar çatışması bulunmamaktadır.

\section{Destek/Teşekkür}

Çalışma sırasında hiçbir kurum ya da kişiden finansal destek alınmamıştır. Çalışmaya katılmayı gönüllü olarak kabul eden ve destekleyen katılımcılara tüm yazarlar teşekkür eder.

\section{Kaynaklar}

Demirtaş, Z. (2017). Eğitimde program değerlendirme yaklaşımlarına genel bir bakış. Sakarya University Journal of Education, 7(4), 756-768. https://doi.org/10.19126/suje.388616

European Network of Occupational Therapy in Higher Education (ENOTHE). (2004b). Occupational Therapy Education in Europe: approaches to teaching and learning "practical" occupational therapy skills. Amsterdam: European Network of Occupational therapy in Higher Education, c/o Hogeschool van Amsterdam.
European Network of Occupational Therapy in Higher Education (ENOTHE). (2004c). Occupational Therapy in Europe: PBL stories and signposts, towards a problem based learning oriented curriculum. Amsterdam: European Network of Occupational therapy in Higher Education, c/o Hogeschool van Amsterdam.

Hodgetts, S., Hollis, V., Triska, O., Dennis, S., Madill, H., \& Taylor, E. (2007). Occupational therapy students' and graduates' satisfaction with professional education and preparedness for practice. Can J Occup Ther, 74(3), 148-160. https://doi.org/10.1177/000841740707400303

Howard, R., \& Lancee, J. (2000). Preregistration education of occupational therapists. Br J Occup Ther, 7(9), 378-381. https://doi.org/10.12968/bjtr.2000.7.9.13851

Lunenburg, F. C. (2011). Self-efficacy in the workplace: Implications for motivation and performance. International Journal of Management, Business, and Administration, 14(1),1-6. 1-6.

http://nationalforum.com/Electronic\%20Journal\%20Volumes/ Lunenburg,\%20Fred\%20C.\%20Self-

Efficacy $\% 20$ in $\% 20$ the $\% 20$ Workplace $\% 20$ IJMBA $\% 20$ V $14 \% 2$ 0N1\%202011.pdf

Sağlık Bilimleri Eğitim Programları Değerlendirme ve Akreditasyon Derneği (SABAK). (2016). Erişim tarihi 30 Mayıs 2019, http://www.sabak.org.tr/index.php/9-blog/85akredite-olan-programlarin-listesi

Sığırtmaç, İ. , Alan, E. , Öksüz, Ç. (2017). Ergoterapi bölümü öğrencilerinin kaygı düzeyleri ile lisans eğitimi ve stajların yeterliliği konusundaki görüşlerinin araştırılması. Ergoterapi ve Rehabilitasyon Dergisi, 5 (1) , 11-20. DOI: 10.30720/ered.585891

Tuning Academy. (2014). Reference Points for the Design and Delivery of Degree Programmes in Occupational Therapy. Erişim Tarihi 21.04.2020 http://tuningacademy.org/wpcontent/uploads/2014/02/RefOccupationalTherapy_EU_EN. pdf

USC Chan Division. (2019). Division of Occupational Science and Occupational Therapy. (2019). Erişim tarihi 29 Mayıs 2019. https://chan.usc.edu/academics/course-descriptions

World Federation of Occupational Therapists (WFOT). (2017). Advice for the Establishment of a New Entry-level Programme for the Education of Occupational Therapists. Erişim tarihi 17 Haziran 2019, https://www.wfot.org/assets/resources/WFOT-Process-forthe-Approval-of-Education-Programmes.pdf

Hacettepe Üniversitesi Ergoterapi Bölümü. (2018). Erişim tarihi 10 Haziran 2019, http://www.ergoterapi.X.edu.tr/

Yükseköğretim Kurulu (YÖK). (2018). Ulusal Çekirdek Eğitim Programı. Erişim tarihi 29 Mayıs 2019 https://www.yok.gov.tr/Documents/Kurumsal/egitim_ogretim _dairesi/Ulusal-cekirdek-egitimiprogramlari/ergoterapi_ulusal_cekirdek_egitim_programi.pdf Yükseköğretim Kalite Kurulu (ty). Eğitim ve Öğretim. Erişim Tarihi 21.Nisan.2020, https://portal.yokak.gov.tr/kategori/egitimogretim-surecleri/ 